доктор экономических наук, профессор, заведующий кафедрой экономики и управления филиала Российского государственного гидрометеорологического университета в г. Tуапсе

Темирова Заира Денилбековна

кандидат экономических наук, старший преподаватель филиала Российского государственного гидрометеорологического университета в г. Туапсе

\section{СРАВНИТЕЛЬНЫЙ АНАЛИЗ ПИЛОТНОГО ПРОЕКТА И ЗАЧЕТНОГО МЕХАНИЗМА СТРАХОВЫХ ВЫПЛАТ ФОНДА СОЦИАЛЬНОГО СТРАХОВАНИЯ РФ}

\section{Аннотация:}

В статье проанализированы зачетный механизм уплаты страховых взносов по обязательному социальному страхованию на случай временной нетрудоспособности и в связи с материнством и пилотного проекта по прямым выплатам Фонда социального страхования РФ. Выявлено, что зачетному механизму свойствен ряд недостатков, в том числе отсутствие возможности эффрективного контроля за расходами ФСС РФ по ОСС на случай ВНиМ, что проявляется в непрозрачности движения соответствующих расходов ФСС РФ. Это может говорить о значительном объеме необоснованных расходов по данному виду страхования, также имеют место задержки или полный отказ в выплате пособий застрахованным. Пилотный проект в свою очередь обеспечивает условия для контроля правомерности назначения, правильности исчисления пособий и достоверности передаваемой страхователем информации. Однако не стоит считать существующий вариант проекта с учетом его недоработок окончательным.

\section{Ключевые слова:}

Фонд социального страхования РФ, обязательное социальное страхование на случай временной нетрудоспособности и в связи с материнством, пилотный проект Фонда социального страхования $P \Phi$, зачетный механизм выплаты пособий, социальное страхование, система контроля за обоснованностью назначения пособий, единая информационная система участников пилотного проекта.
D.Phil. in Economics, Professor, Head of the Economics and Management Department, Tuapse branch of Russian State Hydrometeorological University

Temirova Zaira Denilbekovna

PhD in Economics, Senior Lecturer, Tuapse branch of Russian State Hydrometeorological University

A COMPARATIVE ANALYSIS OF THE PILOT PROJECT

AND THE CREDITING MECHANISM OF INSURANCE PAYMENTS OF THE SOCIAL INSURANCE FUND OF THE RUSSIAN FEDERATION

Summary:

The article analyzes the crediting mechanism for compulsory social insurance contributions in case of temporary disability and maternity and direct payment pilot project of the Social Insurance Fund of the Russian Federation. The study reveals that the crediting mechanism has several shortcomings, including the lack of effective control over expenditures of the Social Insurance Fund of the Russian Federation on compulsory social insurance in case of temporary disability and maternity as demonstrated by low transparency of the related expenditures. This shows the significant amount of unjustified expenses on this kind of insurance, the delayed payment or refusal of benefits to the insured person. In turn, the pilot project ensures the control over the eligibility of granting benefits, their correct calculation and the authenticity of information transferred by the policyholder. However, the current version of the project is not final, as it requires further drafting.

Keywords:

Social Insurance Fund of the Russian Federation, compulsory social insurance in case of temporary disability and maternity, pilot project of the Social Insurance Fund of the Russian Federation, crediting mechanism of benefits payments, social insurance, monitoring system for the validity of benefits, unified information system for participants in the pilot project.

Одной из главных задач социальной политики государства является поддержание стабильности и устойчивого развития общества. Система социального страхования выступает в роли одного из направлений социальной политики, значимость которого в современных условиях постоянно возрастает [1]. Она состоит из четырех видов страхования, финансовые средства которых распределяются между тремя внебюджетными фондами:

- обязательное пенсионное страхование - Пенсионный фонд Российской Федерации;

- обязательное медицинское страхование - Федеральный фонд обязательного медицинского страхования Российской Федерации;

- обязательное социальное страхование на случай временной нетрудоспособности и в связи с материнством (далее - ОСС на случай ВНиМ) - Фонд социального страхования Российской Федерации (далее - ФСС РФ); 
- обязательное социальное страхование от несчастных случаев на производстве и профессиональных заболеваний - ФСС РФ.

В сравнении с другими видами социальное страхование на случай временной нетрудоспособности и в связи с материнством не только возмещает трудовые доходы при наступлении страхового случая, но и способствует росту рождаемости и, как следствие, улучшению демографических показателей России. В общих расходах ФСС РФ расходы по данному виду страхования составляют 76 \%. Доходная часть бюджета этой организации формируется под влиянием всех сорер экономики страны, что указывает на необходимость поддержания бюджета ФСС РФ на соответствующем уровне. Правомерное и эффективное расходование ресурсов ФСС РФ является основой обеспечения государственных гарантий по обязательному социальному страхованию. В связи с этим работающие граждане заинтересованы в их целевом использовании.

За счет средств ОСС на случай ВНиМ осуществляются следующие выплаты:

- пособие по временной нетрудоспособности;

- пособие по беременности и родам;

- единовременное пособие женщинам, вставшим на учет в медицинских учреждениях в ранние сроки беременности;

- единовременное пособие при рождении ребенка;

- ежемесячное пособие по уходу за ребенком.

Указанные пособия можно классифицировать в две группы по их целевому назначению [2]. К первой относятся пособия, полностью или частично компенсирующие утраченный трудовой доход, размер которого зависит от объема заработка и страхового стажа застрахованного лица:

- пособие по временной нетрудоспособности;

- пособие по беременности и родам;

- ежемесячное пособие по уходу за ребенком.

Во вторую группу входят пособия, предоставляемые как материальная помощь. Их размер не зависит от трудового дохода и страхового стажа застрахованного лица, а устанавливается государством в фиксированном размере. Пособия могут быть адресованы как застрахованным, так и гражданам, не подлежащим обязательному социальному страхованию. В их число входят следующие виды помощи:

- единовременное пособие при рождении ребенка;

- единовременное пособие женщинам, вставшим на учет в медицинских учреждениях в ранние сроки беременности.

Как сказано ранее, данные пособия имеют фиксированный характер и не зависят от трудового дохода и страхового стажа застрахованного лица. Наряду с этим на подобную помощь в идентичном размере имеют право граждане, не состоящие в трудовых отношениях и, соответственно, не подлежащие ОСС на случай ВНиМ. Указанные пособия входят в программу демографического развития Российской Федерации, выплачиваются органами социальной защиты населения РФ из средств федерального бюджета РФ. Можно сделать вывод, что часть расходов на выплаты по ОСС на случай ВНиМ обладает страховым характером, другая - очевидно выраженным характером социального обеспечения.

Пособия по временной нетрудоспособности, беременности и родам, уходу за ребенком до достижения им 1,5 лет имеют страховую природу. Доля соответствующих выплат в расходах ФСС РФ в 2016 г. составила 488,4 млрд р., или 95,5 \% от общих расходов по данному виду социального страхования.

Основополагающие черты современной системы ОСС на случай ВНиМ были заложены еще в советское время. В переходный период принципиальных изменений она по существу не претерпела.

В системе ОСС на случай ВНиМ в России можно выделить ряд особенностей. Главными из них можно назвать следующие: данный вид страхования реализуется как часть общей государственной социальной политики; преобладающий объем работы по назначению и выплате пособий ведет работодатель (страхователь); ФСС РФ (страховщик) осуществляет контрольные и организационные функции. Исторически сложившийся в России зачетный механизм функционирования ОСС на случай ВНиМ способствует поддержанию низкого уровня затрат на содержание кадров ФСС РФ, что для ФСС РФ экономически выгодно.

Информацию о расходах страхователи предоставляют в ежеквартальной отчетности в территориальные органы ФСС РФ по месту регистрации. В случае если затраты превышают начисленные страховые взносы, страхователь имеет право обратиться в территориальный орган ФСС РФ за возмещением данной суммы. Возмещение производится после проведения камеральной или выездной проверки документов, послуживших основанием для начисления и выплаты страхового обеспечения. По итогам проверки при отсутствии нарушений сумма возмещается в полном объеме, при наличии нарушений - не принимается к зачету, на нее начисляются страховые взносы. 
Страховые отношения изначально подразумевают страховщика как сторону, реализующую гарантированную государством выплату страхового обеспечения, однако при зачетном механизме он выступает в первую очередь лишь как сборщик страховых взносов. Это создает неясность в разделении ответственности страховщика и страхователя. Также при подобном механизме назначение и расчет пособий по ОСС на случай ВНиМ возлагаются на работодателя, за исключением следующих случаев:

- работодатель ликвидирован;

- на расчетном счете страхователя недостаточно средств (при этом необходимо наличие картотеки 2 на счете, при ее отсутствии выплаты не производятся);

- местонахождение работодателя неизвестно;

- при банкротстве работодателя.

Нередки примеры недобросовестности страхователей, проявляющейся в отказе или неправомерном снижении работникам размера пособия, вызванных полной или частичной неуплатой страховых взносов за наемных работников. В данных ситуациях сотрудник вынужден обращаться за защитой своих прав в правоохранительные органы. Недобросовестность страхователей может быть выражена и в предоставлении недостоверной информации в ежеквартальной отчетности. В частности, страхователь намеренно указывает расходы, которые фактически не имели места, в целях неуплаты страховых взносов. При этом отраженные в отчете расходы учитываются в счет уплаты страховых взносов и за возмещением расходов, в случае их превышения, намеренно не обращаются. Проверить обоснованность таких расходов возможно лишь при проведении плановой выездной документальной проверки совместно с ПФРФ. Однако, как показывает практика, доля охвата аудитами подобных нечестных страхователей довольно низка.

Вместе с тем зачетный механизм обладает рядом преимуществ:

- удобство для застрахованных лиц, так как выплаты пособий производятся в порядке и в сроки, установленные для перечисления заработной платы;

- основные административные и финансовые издержки, связанные с назначением, исчислением и выплатой пособий, возлагаются на страхователя, что является экономически выгодным для ФСС РФ.

При зачетном механизме страхователь осуществляет следующие функции в рамках ОСС на случай ВНиМ:

- гарантирует правомерность назначения и исчисления пособий;

- обеспечивает своевременность их выплат;

- выполняет работу налогового агента при взимании налога на доходы с физических лиц (НДФЛ), при выплате пособий по временной нетрудоспособности;

- в случае необходимости и в установленном порядке удерживает алименты при выплате пособий по временной нетрудоспособности, перечисляет средства на счета заявителя об уплате алиментов.

С одной стороны, перепоручать администрации предприятий функции страховщика экономически выгодно для ФСС РФ, что объясняет долговременное существование данной практики назначения, расчета и выплаты пособий. С другой - хорошо, если контроль страховщика за страхователем постоянный и нарушения немногочисленны, но результаты анализа подтверждают обратное. Так, из таблиц 1-3 видно, что специалисты ФСС РФ ежегодно проверяют не более 4 \% расходов по обязательному социальному страхованию, указанных страхователями в ежеквартальной отчетности. По итогам проверок из общего числа составленных актов 37 \% имеют нарушения.

Таблица 1 - Динамика расходов ФСС РФ по ОСС на случай ВНиМ за 2010-2014 гг. [3]

\begin{tabular}{|l|c|c|c|c|c|c|c|c|c|}
\hline \multicolumn{1}{|c}{ Показатель } & $\mathbf{2 0 1 0}$ & $\mathbf{2 0 1 1}$ & $\mathbf{2 0 1 2}$ & $\mathbf{2 0 1 3}$ & $\mathbf{2 0 1 4}$ & $\begin{array}{c}\mathbf{2 0 1 1} \\
\mathbf{\kappa} \mathbf{2 0 1 0 ,} \\
\mathbf{\%}\end{array}$ & $\begin{array}{c}\mathbf{2 0 1 2} \\
\mathbf{\kappa} \mathbf{2 0 1 1} \\
\mathbf{\%}\end{array}$ & $\begin{array}{c}\mathbf{2 0 1 3} \\
\mathbf{\kappa} \mathbf{2 0 1 2} \\
\mathbf{\%}\end{array}$ & $\begin{array}{c}\mathbf{2 0 1 4} \\
\mathbf{\kappa} \mathbf{2 0 1 3} \\
\mathbf{\%}\end{array}$ \\
\hline $\begin{array}{l}\text { Единовременное пособие жен- } \\
\text { щинам, вставшим на учет в } \\
\text { ранние сроки беременности, р. }\end{array}$ & 321 & 368 & 415 & 448 & 489 & 114,60 & 112,80 & 107,90 & 109,15 \\
\hline $\begin{array}{l}\text { Единовременное пособие при } \\
\text { рождении ребенка, р. }\end{array}$ & 13764 & 15878 & 17287 & 18458 & 19676 & 115,40 & 108,90 & 106,80 & 106,60 \\
\hline $\begin{array}{l}\text { По уходу за ребенком до 1,5 } \\
\text { лет, р. }\end{array}$ & 76097 & 93586 & 101078 & 113512 & 121382 & 123,00 & 108,00 & 112,30 & 106,90 \\
\hline По беременности и родам, р. & 67317 & 75632 & 86636 & 82448 & 95664 & 112,40 & 115,00 & 95,50 & 116,02 \\
\hline $\begin{array}{l}\text { Расходы на пособия по ВН, } \\
\text { млн р. }\end{array} 182476$ & 151691 & 146358 & 163369 & 176415 & 83,10 & 96,50 & 111,60 & 107,90 \\
\hline Число случаев ВН, тыс. шт. & 31606 & 32582 & 28654 & 28090 & 26691 & 103,10 & 87,90 & 87,90 & 90,00 \\
\hline $\begin{array}{l}\text { Общее число оплаченных дней } \\
\text { по ВН, тыс. сут }\end{array} 392606$ & 361341 & 319817 & 314669 & 304020 & 91,90 & 88,70 & 88,70 & 96,60 \\
\hline $\begin{array}{l}\text { Средний размер дневного по- } \\
\text { собия по ВН, р. }\end{array}$ & 464,78 & 419,80 & 457,63 & 516,00 & 580,27 & 90,50 & 108,80 & 108,80 & 112,40 \\
\hline
\end{tabular}


Таблица 2 - Результаты плановых выездных проверок страхователей по выплате страхового обеспечения по ОСС на случай ВНиМ в 2013-2014 гг.

\begin{tabular}{|l|c|c|c|}
\hline \multicolumn{1}{|c|}{ Показатель } & $\mathbf{2 0 1 3}$ & $\mathbf{2 0 1 4}$ & $\mathbf{9}$ мес. 2015 \\
\hline Акты проверок, тыс. шт. & 79 & 78 & 56 \\
\hline Акты проверок, по которым выявлены нарушения, тыс. шт. & 29 & 30 & 22 \\
\hline Расходы, не принятые к зачету, млн р. & 620 & 636 & 468 \\
\hline Восстановлено в бюджет ФСС РФ, млн р. & 582 & 554 & 298 \\
\hline
\end{tabular}

Таблица 3 - Результаты выездных проверок по рассмотрению обращений страхователей о возмещении расходов по ОСС на случай ВНиМ в 2013-2014 гг.

\begin{tabular}{|c|c|c|c|}
\hline Показатель & 2013 & 2014 & 9 мес. 2015 \\
\hline \multicolumn{4}{|l|}{ Обращения страхователей о возмещении расходов: } \\
\hline количество, тыс. шт. & 50 & 51 & 36 \\
\hline сумма, млн р. & 11973 & 13825 & 11063 \\
\hline Акты проверок, тыс. шт. & 50 & 50 & 36 \\
\hline \multicolumn{4}{|l|}{ Решения о выделении средств (частичном выделении): } \\
\hline количество, тыс. шт. & 49 & 50 & 35 \\
\hline сумма, млн р. & 11809 & 13515 & 14900 \\
\hline в том числе удовлетворено частично на сумму, млн р. & 3020 & 3227 & 2667 \\
\hline \multicolumn{4}{|l|}{ отказано: } \\
\hline количество, шт. & 833 & 821 & 518 \\
\hline сумма, млн р. & 99 & 97 & 79 \\
\hline
\end{tabular}

Из изложенного можно сделать вывод, что действующий зачетный механизм не обеспечивает эффективный контроль за расходами ФСС РФ по ОСС на случай ВНиМ. Это проявляется в отсутствии прозрачности движения средств ФСС РФ, что может говорить о значительном объеме необоснованных трат по данному виду страхования, а также нарушении гарантированных государством прав на страховое обеспечение. Указанные недостатки стали причиной предложения пилотного проекта по переходу на прямые выплаты страхового обеспечения непосредственно территориальными органами ФСС РФ.

В соответствии с постановлением Правительства РФ от 21.04.2011 г. № 294 «Об особенностях финансирования, назначения и выплаты в 2011 г. страхового обеспечения, иных выплат и расходов, предусмотренных ч. 2 ст. 7 федерального закона "О бюджете Фонда социального страхования Российской Федерации на 2011 г. и на плановый период 2012 и 2013 гг.", особенностях уплаты страховых взносов по обязательному социальному страхованию на случай временной нетрудоспособности и в связи с материнством и по обязательному социальному страхованию от несчастных случаев на производстве и профессиональных заболеваний» с 01.07.2011 г. началось поэтапное реформирование системы ОСС на случай ВНиМ. Площадками для эксперимента стали Нижегородская область и Карачаево-Черкесская Республика. В 2012 г. в реализации пилотного проекта приняли участие Астраханская, Курганская, Новгородская, Новосибирская, Тамбовская области и Хабаровский край.

По состоянию на 01.07.2017 г. в проекте участвуют 33 региона. Для этого были выбраны разные по социально-экономическому развитию субъекты Российской Федерации в целях определения эффрективности действия предложенного механизма, выявления недостатков и дальнейшего внедрения на всей территории страны.

Пилотный проект предусматривает освобождение страхователей от обязанности назначения, исчисления и выплаты пособий по ОСС на случай ВНиМ, и в связи с этим уплата страхователями страховых взносов производится в полном объеме. Первостепенной целью программы являются обеспечение застрахованных граждан страховыми выплатами независимо от финансового положения работодателя, а также реализация положений федерального закона от 16.07.1999 г. № 165-Ф3 «Об основах обязательного социального страхования», в соответствии с которым обеспечение по обязательному социальному страхованию осуществляется страховщиком.

Опыт реализации пилотного проекта дает возможность обозначить его положительные результаты.

1. Создание эффрективной системы контроля за правомерностью назначения пособий, правильностью их расчета и четкой адресности получателя.

2. Заметное упрощение порядка выплаты пособий застрахованным гражданам, работодатель которых прекратил деятельность либо имеет недостаток денежных средств для реализации данной обязанности. Также это касается организаций, местонахождение которых невозможно установить или проходящих одну из стадий процедуры банкротства.

3. Снижение уровня зависимости застрахованных граждан при получении гарантированных законодательством пособий от действий недобросовестных работодателей. 
Однако вариант модели, реализуемой в рамках пилотного проекта, едва ли можно рассматривать как окончательный, поскольку он имеет ряд существенных недоработок. Действующая схема прямых выплат в силу новизны и отсутствия полноценного электронного документооборота вышла достаточно трудоемкой и во многом, по нашему мнению, неудобной для всех участников. Тем не менее сама идея прямых выплат, на наш взгляд, способна обеспечить эфрфективность оговоренных функций.

Наиболее существенными недостатками модели являются следующие.

1. Механизм выплат, предложенный в пилотном проекте, нельзя назвать «прямым» в полной мере, поскольку застрахованное лицо по-прежнему вынуждено обращаться к работодателю при оформлении необходимых документов, а именно взаимодействие работодателей с ФСС РФ, как правило, вызывает нарекания.

2. Также сохраняется близкий к зачетной технологии компенсационный механизм возврата страхователю средств за произведенные им выплаты некоторых видов пособий, в частности оплата 4 дополнительных выходных дней одному из родителей (опекуну, попечителю) для ухода за детьми-инвалидами, пособие на погребение. Данные компенсации реализуются за счет межбюджетных трансфертов бюджету ФСС РФ из федерального бюджета.

3. Многократно возросла организационная, информационно-технологическая и профессиональная нагрузка на территориальные органы ФСС РФ.

Успешное решение проблем перехода от зачетного механизма возможно в следующих случаях:

- при автоматизации процессов сбора и обработки информации;

- при активном информационном обмене и интеграции сегментов информационной системы (далее - ИС) ФСС РФ на территориальном уровне с аналогичными учреждениями ИС территориальных органов Пенсионного фонда РФ, обязательного медицинского страхования и обслуживания.

По итогам сравнительного анализа зачетного механизма и существующей пилотной модели прямых выплат страхового обеспечения можно сделать вывод, что любые страховые отношения предусматривают роль страховщика как участника, осуществляющего контроль за правомерностью назначения, правильностью исчисления пособий, обеспечивающего застрахованных лиц гарантированными государством страховыми выплатами по ОСС, однако при исторически сложившемся в России зачетном механизме страховщик по ОСС на случай ВНиМ выступает только как сборщик страховых взносов. Кроме того, зачетный механизм создает неопределенность в разделении обязанностей и ответственности между страхователем и страховщиком.

Пилотный проект в свою очередь дает возможность обладать полной информацией об условиях обеспечения пособиями застрахованных лиц на каждом этапе от назначения до выплаты, в то время как при зачетном механизме территориальные органы ФСС РФ получают сведения только о размере выплаченных пособий после проведения выплат при сдаче страхователями ежеквартальной отчетности. Данный факт позволяет снизить объем необоснованных расходов.

В ходе реализации пилотного проекта установлено, что переход на прямые выплаты застрахованным лицам страхового обеспечения страховщиком решает следующие задачи:

1) в корне устраняет проблему выплаты пособий по ОСС на случай ВНиМ застрахованным лицам, работодатель которых имеет финансовые проблемы, фактически прекратил свою деятельность и т. д.;

2) создает эффективную систему контроля за правомерностью назначения пособия и правильностью его исчисления;

3) позволяет сформировать систему мониторинга схем страхового мошенничества, включая методику контроля за фальшивыми бланками листков нетрудоспособности до назначения и выплаты пособий, что невозможно сделать при зачетном механизме.

В рамках действия зачетного механизма для выявления фактов нарушений законодательства Российской Федерации, в частности по оформлению документов, являющихся основанием для назначения и выплаты пособий, территориальные органы ФСС РФ проводят выездные и камеральные проверки страхователя. Такая система контроля за соблюдением законодательства об обязательном социальном страховании недостаточна и позволяет установить минимальное количество нарушений.

При зачетном механизме ФСС РФ не имеет возможности полноценно управлять собственными расходами, чем пользуются недобросовестные страхователи. При этом охват плановыми проверками подобных компаний незначителен. Реализация пилотного проекта меняет сложившуюся ситуацию, так как страхователи перечисляют взносы в полном объеме, а контроль за документами, необходимыми для назначения пособий, осуществляется в 100 \% случаев сотрудниками ФСС РФ.

Однако неизбежные проблемы, связанные с оперативной и своевременной обработкой значительного объема данных, могут быть успешно преодолены территориальными органами 
ФСС РФ лишь при условии введения полноценного электронного документооборота между всеми участниками процесса по назначению и выплате пособий. Также необходимо создание единой информационной системы Фонда социального страхования РФ, Пенсионного фонда РФ, Федерального фонда обязательного медицинского страхования и медицинских учреждений.

\section{Ссылки и примечания:}

1. Яковлева Н.И. Особенности социологического изучения системы социального страхования // Социологический альманах Института социологии НАН Беларуси. 2015. № 6. С. 518-525.

2. Матвиенко К.В. Методика определения круга лиц, имеющих право на получение материальных выплат в связи с утратой трудоспособности или смертью кормильца // Современная научная мысль. 2017. № 1. С. 294-300.

3. Таблицы 1-3 подготовлены на основе данных годовых отчетов Федерального казначейства. См.: Бюджеты государственных внебюджетных фондов [Электронный ресурc]. URL: http://www.roskazna.ru/ispolnenie-byudzhetov/byudzhetygosudarstvennykh-vnebyudzhetnykh-fondov/ (дата обращения: 12.08.2017).

\section{References:}

Matvienko, KV 2017, 'Methods for determining the number of persons entitled to receive material benefits due to loss of ability to work or death of survivor', Sovremennaya nauchnaya mysl', no. 1, pp. 294-300, (in Russian).

Yakovleva, NI 2015, 'Peculiarities of sociological study of the social insurance system', Sotsiologicheskiy al'manakh Instituta sotsiologii NAN Belarusi, no. 6, pp. 518-525, (in Russian). 